\title{
Práticas de sociabilidade na arte contemporânea
}

CRISTINA PRATAS CRUZEIRO

Resumo

Este texto reflecte sobre a constituição da arte enquanto projecto de sociabilidade que se tem projectado a partir da irrupção no real, assente, por um lado, na abdicação do espaço discursivo do artista a um terceiro elemento e, por outro, no comprometimento artístico com o social e o político. 


\section{Abstract:}

This text reflects about the constitution of art as a project of sociability that is being projected from the irruption on the real, based, on the one hand, in the abdication of the discursive space of the artist to a third element and, on the other hand, in the artistic commitment to the social and political spaces. 
O cumprimento da praxis artística faz-se através de três elementos fundamentais: autoria, obra e recepção. Contudo, qualquer análise ao campo de actuação da arte torna evidente que a importância e relevância dada a cada um destes três elementos é variável. Essa variabilidade está obviamente relacionada com factores inerentes aos propósitos artísticos, mas também com o contexto social, histórico, político e económico, pelo que cada momento histórico teve, neste aspecto, determinado relacionamento dominante.

Se, em alguns momentos, a obra, enquanto objecto autónomo, foi considerada o elemento mais relevante para os discursos artísticos, outros houve em que a autoria se sobrepôs à obra, por exemplo, na forma como era entendida enquanto espelho autoral ou reflector da auto-referencialidade do artista. Existiram outros posicionamentos entre estes dois mas, até ao século $\mathrm{XX}$, o relacionamento entre os elementos da praxis artística cumpriu-se essencialmente no binómio artista-obra, numa espécie de movimento autotélico caracterizado pela independência destes dois elementos a um outro - a recepção.

O elemento da recepção (o espectador, o observador, o público) teve, de uma forma geral, um lugar exterior à obra que se manteve até ao século XX. Era um lugar importante, por exemplo ao nível da interpretação ou da representação, mas sem qualquer responsabilidade ao nível da concretização. A obra apresentava-se ao mundo completada pelo artista, ele era a causa da sua existência e o papel do espectador assentava na contemplação, fruição e interpretação privada - era um discurso monologar.

Foi sobretudo a partir do século XX, numa coincidência temporal e espacial ao desenvolvimento tecnológico, a novas leis de mercado e a novas dinâmicas sociais e culturais (que influenciaram de forma inequívoca a imagem social do artista) que este binómio artistaobra começou a ser questionado.

No período comummente entendido por primeiras vanguardas, a descoincidência entre a obra e o autor foi essencial, desviando, em muitas situações, o discurso artístico para a própria obra, ou seja, para as questões axiológicas, formais e filosóficas que a compunham. Isso não determinou uma perda significativa da autoridade conferida ao autor mas retirou-lhe a ligação directa à obra por via da realização física (ready-made, colagem, fotomontagem, etc.) ou da transposição do carácter do artista para a obra (estados de alma, auto-biografia, etc.). 
Conceitos até então fundamentais para a estrutura identitária das artes, como os de original, aura ou manualidade, perderam a sua posição hegemónica quando a reprodutibilidade se tornou uma realidade para o campo artístico. O ensaio de Walter Benjamin, A obra de arte na era da sua reprodutibilidade técnica, escrito em 1936, foi paradigmático neste sentido e sistematizou de uma forma bastante clara esta problemática, tornando evidente que o "valor único" da obra de arte, ao qual se associava a "singularidade" e a "autenticidade", criava um estatuto "aurático" que aproximava o processo de fruição de uma espécie de ritual. Ora, como Benjamin afirmou, "a reprodutibilidade técnica da obra de arte emancipa-a, pela primeira vez na história do mundo, da sua existência parasitária no ritual. (...) Em vez de assentar no ritual, passa a assentar numa outra praxis: a política." (BENJAMIN, 1992, p. 83-84)

Foi sobretudo durante as segundas vanguardas, a partir dos anos 50, que a recepção foi incluída como elemento fundamental para o cumprimento da obra de arte, num processo coincidente à sobreposição da premissa axiológica (o questionamento de valores: modo como se faz arte, a obra) a uma ontológica (o questionamento do ser: o que é a arte, a obra).

Esta nova consciência artística, que alterou de forma substancial tanto o conceito de autoria como o de obra de arte determinou ainda uma alteração ao nível da função da recepção. Por um lado o artista desocupou o lugar quase demiúrgico que tinha, para se posicionar de uma forma mais directa com o mundo que o rodeia e o entendimento da obra de arte, associado a um objecto com estatuto especial, foi alargando cada vez mais o seu campo de possibilidades, até ao momento em que se constituiu como um sistema relacional que, inclusive, dissocia o conceito de "obra" do de "objecto". Por outro lado a recepção desocupou de igual forma o lugar passivo que lhe cabia, sendo-lhe exigida uma participação activa e, muitas vezes, física.

Isto significa que a questão deixou de estar apenas no reposicionamento de cada elemento da praxis para, de igual forma, estar no significado que cada um deles passou a compreender. De um movimento monologar, que começava e se encerrava no artista, nasceu um movimento dialogal, cuja tónica principal assenta na integração da arte no meio colectivo, sustendo-se precisamente na ideia de arte como sistema relacional. 
É assim notório que as práticas artísticas assentes nestes pressupostos traduziram, desde as suas origens históricas, uma predisposição de relacionamento físico com o real. Essa predisposição, presente logo no início do século, com a inserção de objectos e fragmentos do quotidiano nas obras de arte, manteve-se operante, quando, nos finais dos anos 50, a obra de arte atingiu o seu ponto culminante de desmaterialização, constituindo-se como experiência física e táctil, como vivência imediata.

A partir daí, abundam exemplos de propostas artísticas que denunciam uma vontade de trabalhar no contexto artístico a partir do real, procurando uma sociabilidade sem precedentes, que usa como estratégia o vínculo físico já referido, mas que assenta essencialmente no comprometimento político e social com o meio colectivo.

No fundo, essa busca de sociabilidade, radica no pressuposto de que a arte não pertence a uma esfera isolada, independente ou autónoma da vida. Ela comunga do mesmo mundo que o quotidiano, a política, a economia, a religião, etc.

O envolvimento da recepção na constituição física da obra de arte foi uma das mais visíveis manifestações deste pressuposto, uma vez que por via da alteração da dinâmica da praxis artística alterou também os seus alicerces simbólicos. Um dos primeiros autores que reflectiu sobre o assunto, Umberto Eco, sugeriu que estes fenómenos poderiam implicar uma "alteração da sensibilidade estética (ou mesmo da sensibilidade cultural em geral)" e que, portanto, era importante perceber "em que medida podem ser facilmente definidos pelas categorias estéticas actualmente usadas." (ECO, 1986, p.153)

De facto, cinquenta e dois anos depois de Eco ter realizado a sua conferência sobre a obra aberta, tornou-se claro que as propostas artísticas que se apresentam inacabadas ao fruidor, determinam uma análise arredada das categorias estéticas tradicionais assim como uma sensibilidade cultural diferente da existente até então. São práticas artísticas que, embora muito distintas entre si, traduzem um entendimento da arte como plataforma de comunicabilidade e, portanto, o artista adopta estratégias consonantes com esse entendimento, assumindo-se como um propulsor de interactividade e participação no colectivo social. 
1. O projecto completo pode ser visto no site do artista: http:// www.alfredojaar.net/indexı.html (acedido a 23/03/2010.
Hoje, a possibilidade produtiva do fruidor é uma, entre as várias formas de manifestação artística assente na sociabilidade. Mas o envolvimento de forma directa de um terceiro elemento colectivo, que pode actuar como protagonista, participante ou produtor é actualmente recorrente e o seu papel vai para além dos limites da interpretação, da citação ou do simbólico. Constituise como algo palpável, físico e material.

As propostas artísticas que assentam nessa conjuntura, trabalham com motivações que ultrapassam o campo da estética tradicional e em alguns casos, o campo visual. Instalam-se numa dinâmica cultural, mas também social e ética que, desde os anos 80 , tem assumido duas abordagens distintas, embora ambas demonstrem uma tendência para a reconstituição do espaço público a partir das suas idiossincrasias e do pressuposto de que esse espaço se compõe como uma espécie de rede conectiva e heterogénea onde o artista se converte num elemento impulsionador de diálogo e negociação.

Uma das abordagens, presente em inúmeras obras, pressupõe que o artista assuma a condição de investigador visual, que apropria e captura as imagens que circulam no espaço comum para as trabalhar. Nesta abordagem, embora a figura do artista possa estar identificada com uma espécie de etnógrafo (FOSTER, 1999, p. 171), não existe necessariamente a renúncia à presença autoral (muito embora exista aos valores auto-biográficos) nem à mediação entre o artista e o espectador. Existe sim a tendência para que o artista discurse a partir do reposicionamento dos elementos que compõem o mundo quotidiano, como objectos, imagens, documentos ou testemunhos directos.

Um exemplo claro desta abordagem foi o The Rwanda Project que Alfredo Jaar desenvolveu entre 1994 e 2000. O artista recolheu inúmeros materiais - entre imagens e textos - sobre a grave situação humanitária do Ruanda num work in progress de seis anos, do qual resultaram várias instalações apresentadas em contextos diferentes ${ }^{1}$.

Uma das instalações, Untitled 1994 (Newsweek) consistiu em contrapor as capas da revista Newsweek a factos históricos que ocorreram no Ruanda durante o mesmo período, entre Abril e Agosto de 1994. Depressa se chega a uma conclusão: durante semanas, o genocídio que ali estava a ocorrer não mereceu o tema de destaque da revista, cujas capas se centraram em temas 
genéricos ou triviais. A instalação termina com a capa do mês de Agosto de 1994, quando a Newsweek destaca pela primeira vez o genocídio ruandês, que já contava com cerca de um milhão de pessoas mortas. $\mathrm{O}$ artista não precisou de acrescentar nada ao conteúdo da obra nem criou qualquer imagem nova. O seu trabalho consistiu em compilar determinados elementos no mesmo dispositivo que juntos, assumiram um discurso específico. Esta abordagem da arte assenta as suas raízes no solo de uma era que se define de pós-colonialista e que, enquanto tal, procura encontrar espaço para a criação de relações interculturais e intersociais que, muitas vezes, não passam de posicionamentos teóricos. Mas é nesse espaço que cresce a vontade artística de trazer à luz o que não é mostrado, pontos de vista focalizados no cenário diacrónico das nossas sociedades, a partir do principio da alteridade.

Nestes casos, o artista fala a partir do outro, ou seja, em discurso indirecto, criando um espaço discursivo que anteriormente não existia.

É à luz dessa alteridade que as obras de Ursula Biemann podem ser entendidas. O seu trabalho, centrado na migração, mobilidade, género e tecnologia, tem como estratégia essencial a recolha de diversos materiais e dados, provenientes de fontes diversas, incluindo os que a própria produz no terreno, que são compilados em formato vídeo por forma a criar uma análise alargada do tema que está a tratar. Por exemplo, no video-ensaio $X$-Mission ${ }^{2}$ 2008, Biemann explora a problemática dos campos de refugiados palestinianos a partir de uma narrativa que aborda a questão pelos seus variados prismas, articulando o seu discurso a partir do discurso dos próprios habitantes dos campos e de especialistas em várias áreas directamente implicados na questão.

Esta é ainda a mesma abordagem do filme No quarto de Vanda ${ }^{3}$, do realizador português Pedro Costa. Este filme, posicionado também entre a ficção e o documentário, centraliza-se na vida quotidiana de Vanda, uma toxicodependente que vive no bairro das Fontainhas, a norte de Lisboa. É Vanda quem determina o decurso do filme, que é o segundo de uma trilogia do realizador e que pretende explorar a realidade social de grupos marginalizados como os toxicodependentes ou os emigrantes.

A abordagem de encontro com o real não prescinde, nestes casos, de uma obra perene. A sociabilidade da arte assume-se pre-
2. Acessivel através do site http:// www.geobodies.org/o1_art_and_ videos/2008_x-mission/ (acedido a 30/03/2010)

3. Acessível através do site http:// www.atalantafilmes.pt/2001/ quartovanda/ (acedido a 30/03/2010) 
4. O termo "política" é utilizado com o sentido que Jacques Rancière lhe atribui: "La política consiste en reconfigurar la división de lo sensible, en introducir sujetos y objetos nuevos, en hacer visible aquello que no lo era, en escuchar como a seres dotados de la palabra a aquellos que no eran considerados más que como animales ruidosos. Este processo de creación de disensos constituye una estética de la política, que no tiene nada que ver com las formas de puesta en escena del poder y de la movilización de las masas (...)" in RANCIẼRE, Jacques. Sobre Politicas Estética. Barcelona: Universitat Autònoma de Barcelona, 2005, pág. 19.

5. Acessível através do site: http:// www.megafone.net/ (acedido a 30/03/2010) cisamente pelo comprometimento que essa obra tem perante o mundo social. Tratam-se de práticas artísticas que procuram evidenciar as contradições e dinâmicas sociais a partir dos elementos que a própria realidade disponibiliza. Assim, o artista, procura, investiga, capta, recolhe e selecciona os materiais, com o objectivo de reconstruir essa realidade. Dessa atitude, resultam obras que naturalmente reflectem o sentido crítico dos seus autores, como os exemplos citados, mas a partir de elementos exteriores que discursam por si mesmos.

Na segunda abordagem, o artista assume um posicionamento distinto e renuncia por completo à presença autoral para se tornar em activista, em impulsionador de encontros. Tratam-se de práticas relacionais ou colaborativas onde o fazer artístico se dilui no contexto da realidade, não resultando daí, necessariamente, uma obra perene. A intervenção interactiva ou social transforma-se num fim em si mesmo pelo que a arte retira-se, com frequência, do domínio de trabalho com a imagem, embora se mantenha no perímetro da imaginação (que não é exclusivo da arte), para se fundir com a praxis social e política ${ }^{4}$. Nestes casos, a mediação entre o artista e o espectador deixa de existir e o trabalho é direccionado para determinado colectivo ocasional ou premeditado.

A arte colaborativa, onde os artistas trabalham com colectivos sociais, totalmente implicados com os seus propósitos tem, regra geral, a função de atrair o composto social para determinada causa. Exactamente por isso é comum que o sujeito artista seja um sujeito activista que utiliza a criatividade implícita à sua actividade profissional em prol da comunidade com que se propõe trabalhar.

O artista espanhol Antoni Abad dirige desde 2003 o projecto megafone.net ${ }^{5}$, que consiste em convidar grupos de pessoas em risco de exclusão social a expressar as suas experiências de vida, opiniões e sugestões através de vários encontros ou de dispositivos, como os telemóveis, que permitem aos participantes criar registos de som e imagem e publicá-los directamente na Internet. Até ao momento foram desenvolvidos dez projectos com colectivos distintos: em 2004 com taxistas (México), em 2005 com ciganos (Lérida e Léon) e com prostitutas (Madrid), em 2006 com imigrantes nicaraguenses (Costa Rica), em 2007 com motociclistas (motoboy) em São Paulo e em 2009 com saharauis deslocados em campos de refugiados, na Argélia. O megafone. net, para além de funcionar como plataforma digital, tem a ca- 
racterística de ser financiado por instituições culturais onde são expostas as imagens, vídeos e outros materiais resultantes do trabalho desenvolvido por estes grupos e às quais se associam obras realizadas por outros artistas. Antoni Abad, numa entrevista, foi claro quanto aos seus objectivos: "O que estou fazendo é desviar fundos que estão destinados à arte e à cultura para outro território, mais social, no qual certos colectivos possam auto-representar-se. Eu tenho a possibilidade de fazer isso porque tenho uma trajectória como artista. Então, quando recebo convites para fazer projectos, proponho esses experimentos". ${ }^{6} \mathrm{~A}$ questão que estes projectos colocam para a arte, está expressa nas palavras do artista. Ele afirma que quando recebe convites de instituições artísticas para desenvolver um projecto, as desvia para outro território, que é o social. Mas, ao fazê-lo, arte e social transformam-se no mesmo território.

Assim, estamos perante o reconhecimento de uma actividade artística totalmente nova, que se caracteriza pela criação de plataformas que têm em vista a melhoria imediata das condições de vida das pessoas envolvidas no projecto e, consequentemente, da comunidade inteira a que pertencem.

A arte colaborativa pode ainda tomar corpo através de colectivos onde os artistas se integram com o propósito de colaborar com causas locais, como a criação de determinadas infra-estruturas de bairro, com reivindicações relacionadas com a melhoria do espaço urbano e público. São muitos os exemplos de colectivos de acção directa, sobretudo nas grandes metrópoles. Nos EUA, o Group Material começou a trabalhar na década de 80 já com propósitos claramente sociais, como os projectos que desenvolveram nos subúrbios de Nova Iorque. Em 1986, na brochura que acompanhou a exposição Mass, definiam-se como "A New York City-based organization of artists dedicated to the creation, exhibition, and distribution of art that increases social awareness. ${ }^{7 "}$ No Brasil, com uma tradição que vinha já dos anos 60/70 de artistas que pensavam a inserção da arte no colectivo - como Hélio Oiticica, Ligia Clark, Cildo Meireles, etc. - desenvolveuse, na década de 9o, sobretudo em São Paulo, uma forma de colectivismo artístico pautada por um forte activismo político e social como os colectivos Viajou sem passaporte ou Contrafilé. Em Espanha, o La Fiambrera foi um dos colectivos mais importante dos anos 9o, com o qual colaboraram vários artistas, emersos em processos sociais complexos. Em Portugal, este tipo de colectivismo artístico não tem tido uma expressão continuada
6. ABAD, Antoni (2007). 'Entrevista com Antoni Abad'. In Antroposmoderno (Consult. 02-04-2010). Disponível em «http://www.antroposmoderno. com/antro-articulo.php?id_ articulo=1165"

7. ABAD, Antoni (2007). 'Entrevista com Antoni Abad'. In Antroposmoderno (Consult. 02-04-2010). Disponível em «http://www.antroposmoderno. com/antro-articulo.php?id_ articulo=1165" 
8. Maçãs de Carvalho, José. Lisboa, capital do nada. In PEREZ, Miguel Von Hafe. Anamnese:

O livro. Porto : Fundação Ilídio Pinho, 2006, pág. 418

9. A arte relacional foi definida por Nicolas Bourriaud como "conjunto de prácticas artísticas que toman como punto de partida teórico y práctico el conjunto de las relaciones humanas y su contexto social, más que un espacio autónomo y privativo." In BOURRIAUD, Nicolas. Estética Relacional. Buenos Aires: Adriana Hidalgo Editora, 2008, pág. 142. ou forte. Existiram alguns colectivos com propósitos colaborativos, como o Caldeira 213, no Porto, que encerrou em 2002, ou o Ateliers Mentol, também radicado no Porto desde 2003, que desenvolveu algumas acções com a finalidade de alertar para o processo de desertificação da baixa portuense. Mas tem sido mais frequente que este trabalho, em Portugal, se desenvolva em projectos pontuais como o que José Maçãs de Carvalho desenvolveu em Marvila, em 2001, integrado no evento Lisboa, capital do nada. O projecto do artista teve em vista dar visibilidade a um dos bairros mais estigmatizados de Lisboa, a partir das actividades desenvolvidas pelos moradores. A estratégia adoptada foi criar uma "pseudo-campanha publicitária", como o próprio referiu, divulgando em diversos meios publicitários - mupis, cartazes, postais e anúncios publicados em revistas e jornais - as fotografias dos moradores e um número de telemóvel para onde se deveria ligar caso existisse interesse em conhecer as actividades de cada um deles. Segundo Maçãs de Carvalho, "as pessoas representadas nestes suportes publicitários, receberam centenas de telefonemas e marcaram centenas de encontros para mostrar as suas actividades, tornando-se assim, por momentos, heróis do quotidiano a partir da sua vida real." ${ }^{8}$ Ainda que efémero, este projecto, que teve a colaboração de várias instituições, centrouse de igual forma, tal como nos projectos já aqui citados, em mostrar uma comunidade ou grupo social a partir de um ponto de vista alternativo ao que normalmente é mostrado.

No que se refere à colaboração de artistas em colectivos ou movimentos sociais, o financiamento institucional, regra geral, não se coloca. O artista que se insere nestes colectivos tem que lidar com desafios diferentes, nomeadamente a adaptação à realidade que encontra, aos materiais disponibilizados pelo colectivo e às condições de trabalho existentes na altura, que determinam uma estratégia de adaptação que pode chegar a anular, por exemplo, a possibilidade do artista trabalhar nos meios que domina, como a fotografia ou o vídeo. Nestes casos, a sua função, mais que a de um profissional, é a de criativo.

Neste aspecto, a arte relacional ${ }^{9}$ funciona num prisma diferente, uma vez que o artista, embora funcione igualmente como um potencializador de sociabilidade, fá-lo em torno da comunidade artística, ou seja, cria plataformas de consenso, enquanto que a arte colaborativa procura partir de estruturas não-consensuais. Um exemplo de arte relacional, bastante citado por Nicolas Bourriaud, é o trabalho que o artista Rirkrit Tiravanija desenvolve e 
que consiste em transformar a arte num ponto de encontro. $\mathrm{Na}$ Bienal de Veneza de 1993, o artista apresentou Aperto, uma obra que consistiu em montar um espaço improvisado semelhante a uma cozinha, onde estavam um fogão com água permanentemente ao lume e várias caixas de sopa chinesa desidratada. $\mathrm{O}$ público era convidado a entrar nesse espaço, preparar a sopa que aí lhe era oferecida e estabelecer um convívio tanto com o artista como com as restantes pessoas que ali estivessem. Este projecto, tal como muitos outros definidos no contexto da arte relacional, teve como objectivo criar um espaço pontual de interactividade e comunicação entre os presentes.

Embora em ambos os casos exista uma estratégia de trabalho semelhante, em alguns aspectos os efeitos pretendidos e conseguidos são distintos. A arte relacional privilegia o acontecimento efémero cujo intuito é restaurar o vínculo social temporariamente quebrado pelas sociedades individualistas e solitárias em que vivemos. Já a arte colaborativa funciona como plataforma de negociação social e política e portanto pretende que existam consequências e efeitos consistentes do trabalho desenvolvido.

Em traços muito breves, as duas abordagens aqui referidas, partilham o facto de se traduzirem num entendimento da arte como prática de responsabilidade social, embora a partir de múltiplas dimensões. Assim, em ambos os casos, são utilizadas estratégias semelhantes: a dissolução da autoria, a abdicação do espaço discursivo do artista a um terceiro elemento e a criação de um espaço novo para a arte que é o do diálogo, do confronto e da negociação com o social.

\section{Referências bibliográficas}

ABAD, Antoni (2007). 'Entrevista com Antoni Abad'. In Antroposmoderno (Consult. 02-04-2010). Disponível em <http://www.antroposmoderno.com/antro-articulo.php?id_articulo=1165>

ADORNO, Theodor W. Teoria Estética. 1. ․ㅡ Ed. Lisboa: Edições 70, 1993, $294 \mathrm{p}$.

ALMEIDA, Bernardo Pinto de. Transição - Ciclopes, mutantes, apocalípticos. A nova paisagem artística no final do século XX. 1. ed. Lisboa: Assírio \& Alvim, 2002, 335 p. 
BARTHES, Roland. Ouevres complètes. Tome II (1966-1975). França: Editions du Seuil, 1994.

BISHOP, Claire (Ed.). Participation. 1. Art Gallery, 2006, 240 p.

BISHOP, Claire. Antagonism and relational aesthetics. October. Massachussets, 110, pp. 51-79, Fall 2004.

BENJAMIN, Walter. Sobre Arte, Técnica, Linguagem e política. Lisboa: Relógio D’Água Editores, 1992, 235 p.

BOURRIAUD, Nicolas. Estética relacional. 2..ed. Buenos Aires: Adriana Hidalgo editora, 2008, 143 p.

BOZAL, Valeriano (Ed.). Historia de las ideas estéticas y de las teorias artísticas contemporâneas. 1. e․ ed. Vol II. Madrid: La Balsa de la Medusa, Visor, 1996.

CRUZEIRO, Cristina Pratas. A caminho da dissolução: A problemática da autoria na arte contemporânea. 2006. 187 f. Dissertação (Mestrado em Teorias da Arte) - Faculdade de Belas Artes, Universidade de Lisboa, 2006.

ECO, Umberto. Obra Aberta. 1. ed. Lisboa: Difel, 1989.

FOSTER, Hal. The Return of the Real. 3. ${ }^{\text {a }}$ ed. Mass/London: The MIT Press, 1999, 299 p.

JAUSS, Hans Robert. Las transformaciones de lo moderno. Estúdios sobre las etapas de la modernidade estética. 2.. ed. Madrid: Machado Libros, 2004, 256 p.

LYOTARD, Jean François. A condição pós-moderna. 3. - ed. Lisboa: Gradiva, 2003.

LIPOVETSKY, Gilles. A Era do Vazio. Ensaio sobre o individualismo contemporâneo. 1.e․ Lisboa: Relógio D’Água, 1989, 204 p.

MIRANDA, José Bragança de. Teoria da Cultura. Lisboa: Século XXI, D.L, 2002.

MARCHÁN, Simón (Comp.). Real/Virtual en la estética y la teoria de las artes. 1. ed. Barcelona: Paidós Estética, 2006, 271 p. 
PEREZ, Miguel Von Hafe. Anamnese: O livro. Porto : Fundação Ilídio Pinho, 2006

PERNIOLA, Mário. A arte e a sua sombra. 1. a ed. Lisboa: Assírio \& Alvim, 2006, $120 \mathrm{p}$.

RANCIÈRE, Jacques. Sobre Politicas Estética. Barcelona: Universitat Autònoma de Barcelona, 2005.

THOMPSON, Nato. A guide to democracy in America. Nova Iorque: Creative Time Books, 2008

VATTIMO, Gianni. O fim da Modernidade - Niilismo e Hermenêutica na Cultura Pós- Moderna. 1. a ed. Lisboa: Editorial Presença, 1981.

VIRILLIO, Paul. A inércia polar. 1. a ed. Lisboa: Publicações Dom Quixote, 1993.

\section{CRISTINA PRATAS CRUZEIRO}

Investigadora associada da Secção de Investigação e de Estudos em Ciências da Arte e do Património - Francisco de Holanda, do CIEBA - Centro de Investigação e de Estudos em Belas-Artes, Faculdade de Belas Artes da Universidade de Lisboa. Desenvolve Doutoramento na mesma Instituição na área das Ciências da Arte, com o tema "A condição protésica na arte contemporânea" enquanto bolseira da Fundação para a Ciência e Tecnologia, Ministério da Ciência, Tecnologia e Ensino Superior, Portugal.

E-mail: cristinacruzeiro@gmail.com 